GESCHICHTE UND KRITIK

DER

\title{
GRUNDBEGRIFFE DER GEGENWART.
}





\section{GESCHICH'TE UND KRITIK}

DER

\section{GRDNDBEGRIFFE DER GEGENWART.}

vos

\section{RUDOLF EUCKEN, PROFESSOR IN JEAA.}

\section{LEIPZIG}

VERLAG VON VEIT \& COMP.

1878. 
Druck von Fischer \& Wittig in Leipzig. 